\title{
Theoretical study predicting the biological activities of eugenol, curcumin and cinnamic aldehyde and their combined products: Synergism between natural products for human body's immunity
}

\author{
Bachir Zouchoune ${ }^{1}$ \\ ${ }^{1}$ University of Constantine 1 Department of Chemistry
}

August 11, 2020

\begin{abstract}
DFT/B3LYP calculations have been carried on natural products of eugenol (clove) cinnamic aldehyde (cinnamon) and curcumin (curcuma) and on their various combinations predicting their biological activities. Our findings show that the presence of either cinnamic aldehyd or curcumin ameliorates the biological activities with the regard to the calculated chemical descriptors. The molecular structures of the studied compounds are evaluated on the basis of the intermolecular interactions which are governed by hydrogen bonds. The cinnamic aldehyde synergizes well with the curcumin as combinations of two and with curcumin and ascorbic acid as three components seeing the resulting chemical descriptors, in agrrement with the reduction the HOMOLUMO gaps and suggesting numerous and interesting biological activities. However, eugenol exhibits low chemical descriptors as individual compound and combined with either ascorbic acid or hesperidin. The combined complexes of cinnamic aldehyde could be excellent blood thinners with the regard to their polarity's enhancement. The combined compounds of cinnamon and curcuma should have broad biological properties that advance human health and help to reduce the menace of diseases.
\end{abstract}

\section{Hosted file}

Manuscript_IJQC.docx available at https://authorea.com/users/349780/articles/475131theoretical-study-predicting-the-biological-activities-of-eugenol-curcumin-and-cinnamicaldehyde-and-their-combined-products-synergism-between-natural-products-for-human-bodys-immunity 